\title{
Sexual Identities in EFL at Primary School Level: A Pre-service Teachers' Perspective from Spain
}

\author{
STEFANO BAROZZI \\ JuAN RAMÓn GuiJarRo OJEDA \\ University of Granada
}

Received: 16 March 2014 / Accepted: 14 November 2014

ISSN: $1697-7467$

\begin{abstract}
This article is principally inspired by queer theory and is based on the evaluation of a questionnaire on sexual identity issues directed to ten Spanish pre-service primary school EFL teachers. It aims to show their knowledge of queer issues and their opinion on introducing and discussing sexual identities in EFL at primary school level. The main results highlight the participants' lack of training in this field and a willingness to treat these issues in primary school education. In the paper, sexual identities are generally referred to as lesbian, gay, bisexual, trans, intersexual as well as heterosexual people. It is the first research study realised in Spain that combines primary school education within sexual identity issues in English language teaching.
\end{abstract}

Keywords: English as a Foreign Language (EFL); primary school education; queer theory; homophobia; heteronormativity.

Identidades sexuales en inglés lengua extranjera de Primaria: Perspectivas de docentes españoles en formación

RESUMEN: Este trabajo está principalmente inspirado en la teoría queer y se basa en la evaluación de un cuestionario sobre temáticas relacionadas con las identidades sexuales dirigido a diez docentes en formación de Primaria de lengua inglesa. El objetivo de este estudio es mostrar cómo se perciben estos temas y qué opinión tiene el grupo participante sobre la introducción y la discusión de temáticas queer en inglés lengua extranjera (EFL) de primaria. Los resultados principales destacan la ausencia de formación en este campo y la voluntad por parte del grupo participante de tratar las temáticas queer en la educación primaria. En el artículo las identidades sexuales se refieren principalmente a lesbianas, gays, bisexuales, trans, intersexuales y también heterosexuales. Es el primer estudio realizado en España que combina la educación primaria con las identidades sexuales en la enseñanza de la lengua inglesa.

Palabras clave: Inglés como lengua extranjera (EFL); educación primaria; teoría queer; homofobia; heteronormatividad. 


\section{INTRODUCTION}

This article reports on the outcomes of a qualitative research carried out at the Faculty of Education of the University of Granada in Spain. The justification of this study is founded on the need to discuss and counter homophobia and heterosexism in primary school education as instances of social injustice and discrimination. The importance and the urgency to treat sexual identity issues in EFL teaching has been demonstrated by other studies undertaken by Barozzi (2010), Guijarro and Ruiz (2013) or Barozzi and Guijarro (2014).

Lgbti (lesbian, gay, bisexual, trans and intersexual) adolescents are at much higher risk of attempting or committing suicide than their heterosexual counterparts, as stated in a recent Spanish report carried out by FELGTB (2013), which underlines the failure of the Spanish educational system in its attempt to stop homophobic bullying in education. We prefer to write the acronym lgbti in small letters because we believe that capital letters stand out almost aggressively in a text and it should be read like any other word; moreover, we use the more inclusive term 'trans' in this paper to include both transgender and transsexual people. Intersexual people used to be known as 'hermaphrodites', a derogatory term nowadays. Gender non-normative children start their struggle at an early age when homophobia and transphobia are perceived (Robinson and Jonas Díaz, 2006), hence the need to take action in education as early as possible.

Queer is a problematic term per se, as academically it is understood both as an umbrella term for lgbti and also as a fluid term which rejects fixed categorisations (Jagose, 1992) and supports all individuals who do not feel comfortable with their 'assigned' sexual identity and role. However, to make it simpler in this paper, 'queer identities' is used as a synonym for lgbti people, whilst 'sexual identities' also includes heterosexuality, which, according to queer theory, should be problematised by discussing its hegemonic role in our society (Foucault, 1976; Butler, 1990). Normally, queer issues are not included or discussed in English language teaching at primary school level in Spain, and this is the main problem of our study: the lack of queer didactic materials and discussion in EFL primary education in Spain (heterosexuals are always rendered visible in EFL, hence the use of the term 'queer'). As for our hypothesis, we predict that the participants have never received any training on how to counter homophobia and heterosexism in education.

The principal aim of this study is to discover the participants' knowledge of and opinion on these issues and, according to their answers, whether some basic foundations of queer theory could be applied to EFL at primary school level. Our research is supported by some Spanish and international studies (e.g. Bickmore, 1999; Pichardo Galán et al., 2007) which report that homophobia and heterosexism are rampant in primary and secondary education.

As for the terminology used in this article, sexism is systematically associated with heterosexism, which is the belief that heterosexuality is the only possible natural sexual identity whilst all the others are considered inferior and deviant. Heteronormativity, with its social norms and codes, perpetuates heterosexism and homophobia in education and it is often subconsciously reproduced in everyday interactions, texts, images and discourses. An example of heteronormativity is the total absence of queer individuals in primary school English language textbooks and the tendency of avoiding any discussion and references on the issue in education.

English language teaching has become one of the most important school subjects throughout the world and it is intrinsically connected to social identities; nevertheless, apart 
from heterosexuals, sexual identities are consistently omitted in EFL and ESL (English as a Second Language) education (Thornbury, 1999, Nelson, 2009). We believe that the absence of queer discussions through critical thinking in EFL primary education contributes to the perpetuation of homophobia and heteronormativity which should be considered social injustices just like racism and social discrimination, which Madrid (2011) discussed in relation to the EFL class, or sexism, classicism and different abilities, which instead are sometimes addressed in English language education. In Spain, gender differences in EFL have been analysed by García (2006), but not through a queer perspective.

With regards to the legal situation in Spain, sexual orientation, personal identity and individual differences in education are protected by the Spanish Constitution (1978), and the Educational Legislation (2006). In both state-run and, to a lesser extent, private and religious (Catholic) Spanish primary schools, sexual identity issues could be addressed through cross-curricular themes in almost any school subject, but they are never part of the explicit curriculum. Despite a progressive Spanish legislation (e.g. same sex marriage and child adoption since 2005), EFL publishers (from Britain) are wary of depicting homosexual family units or lgbti individuals in EFL textbooks for primary education as children are deemed to be asexual and too young and naïve to understand the issues involved (Herdt and Boxer, 1993). Yet, primary school pupils are perfectly capable of critical thought when exposed to a whole range of other social issues (Sears, 1999).

One particular research undertaken at the Faculty of Education in the University of Malaga in Spain (Gallardo and Escolano, 2009) underlines the necessity for university students as well as professors to receive professional training on how to treat sexual identity issues in education in every pedagogical area.

\section{TheOretical FRAMEWORK}

\subsection{Queer theory in primary education}

Queer theory started with, or was caused by, the Aids crises of the mid 1980s and early 1990s in the United States and stems from poststructuralism. Poststructuralists consider identities as social and cultural constructs, with people acting out their own social identity on a daily basis in specific ways according to a particular culture, time and space (Butler, 1990; Nelson, 2009).

Queer theory problematises heterosexuality because of its hegemonic role in society. This approach could be very useful in primary education since it enables pupils to conduct more inclusive discussions and to question the hegemony of heterosexuality rather than only discussing subordinate sexual identities in an uncritical way without challenging power relationships in society (Foucault, 1976); hence, queer theory promotes and facilitates inquiry in education.

Primary school pupils already possess much (mis)information about sexual identities and queer issues which needs to be readdressed and reoriented (Chasnoff and Cohen, 1996/2006). Jennings (1999) reports that antigay prejudice starts as early as kindergarten and becomes more manifest among pupils and often teachers in primary education. As Sears suggests (1999: 7), "the question, thus, for educators who teach queerly is not what causes homosexuality, but what factors contribute to the homophobia and heterosexism that make coping with one's sexual orientation so difficult". He also reminds us that: 
With the emergence of the schooling industry, during this century, desire has been masculinised and innocence institutionalised. Acknowledging children as sexual beings or allowing males (particularly homosexuals) to teach in elementary grades dislodges the classroom from the 'safe haven' of heteronormativity (1999: 9).

This statement is strictly related to our study, as some participants expressed cautiousness to treating sexual identity issues with primary school pupils, as if these were asexual beings incapable of having sexual impulses and, above all, recognising and discussing different social gender identifications. Six out of ten participants who took part in this study were men: this representation does not reflect reality as normally there are many more women than men teaching EFL at primary school level. This is one of the reasons we accepted that $60 \%$ of our cohort was formed by men as we wanted to hear their voices in this field usually dominated by women.

Supported by our belief that queer theory could be applied to primary education in this study, Sears describes the content of the book Queering Elementary Education as "creating elementary classrooms that challenge categorical thinking, promote interpersonal intelligence, and foster critical consciousness" (1999: 5). Furthermore, Bickmore (1999) states that it is necessary to discuss sexuality with primary school pupils to enable them to develop their own personal and political lives, to build their autonomy and confidence to deal with difficult situations, conflicts, and differing viewpoints and to learn decision-making skills. Unfortunately, discussions on sexual identities are systematically avoided at primary school level. As a consequence, teacher training programmes on the issue are necessary, and our questionnaire could be considered as a pilot study towards this objective.

The documentary It's elementary. Talking about gay issues in schools (Chasnoff and Cohen, 1996/2006), filmed between six U.S. elementary and middle schools, deals with children's evolutionary age and it is a milestone in the development of didactic discourse in primary and secondary teacher training programmes on sexual identity issues. The movie shows that it is possible to establish constructive discussions with primary school pupils on gay and lesbian issues in a natural and critical way. The pre-service primary school teachers' view and contributions in this study are essential if we intend to promote social equity in education.

\subsection{Sexual identities in English language teaching}

There is no much research in the field of sexual identities within EFL/ESL education, as Nelson puts it "there were few, if any, resources offering guidance in dealing with the intriguing teaching dilemmas that arose with regard to sexual identities" (2009: xiv). She also stresses that queer studies in foreign language teaching are part of a "nascent area and have yet to engage with international contexts and globalised research as much as one would expect" (2009: 26).

Cynthia D. Nelson is an English language teacher and researcher who has published various articles on sexual identities in English language education and also published the first book in 2009 to be written on this issue. Her research has been carried out mainly in conjunction with students and teachers of English as a second language (ESL), therefore her studies differ from ours because they are not addressed to primary school education, but they deal with adult education and ESL. 
According to Nelson (2002), from a teaching and learning perspective, there are many advantages in considering sexual identities as culturally readable acts rather than universal essences. Sexual identities can in fact be regarded as interactive daily performances where the focus is not on what people are, but rather on what they say and do (observable behaviour), as a result, sexual identities as social performances can be interpreted differently in different contexts. Furthermore, teachers, educators, trainers and facilitators are not expected to transmit knowledge they may not have, but to encourage investigation and inquiry (Nelson, 2002). Another important pedagogical component of queer theory is that it adopts a universalising approach to deal with all types of sexuality rather than a minoritising focus that merely concerns itself with the 'heterosexual/homosexual' dichotomy. Most questions used in the survey for this paper reiterate these positions and promote critical thinking amongst the participants of this study.

We have analysed some EFL textbooks (British publishers) for primary education in Spain, and have noticed how heteronormativity is present in almost every unit of the textbooks examined (e.g. Blair and Cadwallader, 2009; Read and Soberón, 2009). Some queer didactic examples for EFL education in Spain are offered by Guijarro (2006).

\section{RESEARCH PROCESS}

\subsection{Participants and Context}

The study was conducted at the Faculty of Education in the University of Granada in Spain, one of the most prestigious in the field of pedagogy in the country. The ten participants were - or had been - all teacher students at the Faculty and were contacted directly by the researchers. After having contacted thirty possible candidates, six men and four women, all Spanish nationals, agreed to participate voluntarily in the study. As mentioned earlier on, it is mainly women who follow this study and profession, so it was interesting to analyse six men's opinion on the subject.

Table 1. Participants' main variables.

\begin{tabular}{|l|c|l|l|}
\hline \multicolumn{1}{|c|}{ GENDER } & AGE & \multicolumn{1}{c|}{ SEXUAL IDENTITY } & \multicolumn{1}{c|}{ RELIGIOUS } \\
\hline WOMAN 1 (W1) & 21 & Not fixed. Possibly bisexual & Yes (Catholic) \\
\hline WOMAN 2 (W2) & 21 & Heterosexual & No \\
\hline WOMAN 3 (W3) & 23 & Not clearly defined. Mainly heterosexual & Yes, but not follower \\
\hline WOMAN 4 (W4) & 23 & Heterosexual & Yes (Catholic) \\
\hline MAN 1 (M1) & 25 & Heterosexual & No \\
\hline MAN 2 (M2) & 30 & Not fixed. Mainly heterosexual & Agnostic \\
\hline MAN 3 (M3) & 30 & Heterosexual & Not much \\
\hline MAN 4 (M4) & 31 & Heterosexual & No \\
\hline MAN 5 (M5) & 32 & Not fixed. Possibly bisexual & No, but spiritual \\
\hline MAN 6 (M6) & 33 & Homosexual & No \\
\hline
\end{tabular}




\subsection{Research Instrument and data analysis}

A questionnaire was sent on-line, which was divided into four main sections:

a) Personal questions; b) Knowledge of queer issues; c) Sexual identity issues in primary school education; d) Queer issues in EFL primary education.

We formulated some of the questions ourselves, while others were drawn from different sources and previous international questionnaires - often modified for our purposes (Harris, Nightingale and Owens, 1995; Herek, 1998; Nelson, 1999). The questionnaire was positively evaluated by experts in the area of qualitative research in education and foreign language teaching at the University of Granada in Spain.

Some of the English terminology and concepts used in the questionnaire could be perceived as difficult and problematic to understand. However, it was not our intention to make it complicated, rather, we wanted to assess their general knowledge of queer issues and relevant terminology such as straight, heteronormativity, queer theory and lgbti.

The online questionnaire data were analysed using qualitative research procedures. Our work is based on a naturalistic inquiry approach, in which participants' voices are central. As in all qualitative research data, we had to take into account each participant's answer and point of view for every question; thus the data analysis resulted to be quite complex. Consequently, for the purpose of this article, we had to concentrate on some of the most relevant contributions made by the participants. Some of their responses were similar, so that we could draw some general conclusions, but others were unique and we also had to take them into account. The questionnaire was written in English, but participants were allowed to answer in Spanish in order to express themselves more freely.

\section{Results AND Discussion}

\subsection{Personal questions}

In this section the participants' responses have been summarised. They all stated that they had queer friends or relatives, and their attitude towards queer people was very positive. In previous research (Hereck, 1998), it was demonstrated that people who do not have queer friends or relatives tend to underestimate homophobia and heterosexism and have more negative attitudes towards lgbti people. The voluntary participants showed positive attitudes towards the issue and therefore the results of this study might reflect this. Their educational background is relatively high since they all have a university level.

In relation to their sexual identity, as shown in Table 1, only half of the cohort admitted being purely heterosexual, although just one person considered himself to be gay (M6). The other four could not define their sexual identity precisely. We were surprised to realise this and that they wrote about their sexual identity freely, which might be easier to do in a written anonymous questionnaire.

The religious participants did not express more negative opinions on sexual identities than the non religious ones. All the participants felt that discussing queer issues at primary school was pertinent to their field of work, thus giving more relevance to the study. 


\subsection{Knowledge of queer issues}

1. What do 'queer' (as in queer theory) and 'lgbti' mean? And what are heterosexism and heteronormativity?

All the participants generally understood the meaning of the acronym 'lgbti', although the term intersexual (i) was unfamiliar to eight of them. On the other hand, seven participants did not know the meaning of 'heterosexism' and 'heteronormativity', only W1, W3 and W4 knew what 'queer' meant in the context of queer theory. M1 and M4 recognised the term 'queer' only as a synonym for lgbti, whilst W4 criticised queer theory:

For me queer theory does not make sense because gays, lesbians, transsexuals, etc. are not actors that play a role during their life and they don't perform their identity as a social construction because, in my opinion, people with different sexualities have always existed, but in the past they were not accepted whilst nowadays, in our democratic society, it is easier for them to be more visible, and that's why there is a polemic against homosexuality.

This statement denotes good critical thinking, however, in accordance to Butler (1990) and Nelson (2009), we believe that sexual identities read as social identities that change in time and place might be easier and probably more appropriate to discuss and apply to primary school EFL education.

\section{Is it easy to identify someone as gay/straight/lesbian in Spain, in Granada?}

Five participants observed that it is easy to identify someone as gay and a bit less as a lesbian, even if they admitted that sometimes these identifications are the result of stereotyping; five argued that they cannot really tell if someone is gay or lesbian, or they can only guess it from their gestures and/or behaviours. Surprisingly, nobody mentioned if it is easy to identify a straight person.

This question was asked on purpose, as we wanted to know whether the participants would pay attention to the word 'straight' and would try to include it in the discussion. It seems a common pattern to avoid talking about heterosexuality when discussing sexual identities, as heterosexuality, according to heteronormativity, cannot be problematised or even discussed. However, educators need to be aware that excluding heterosexuals from gender discourses reinforces their status and subordinates all other sexual identities.

\section{What do you think caused your 'heterosexuality'?}

This question was created by Martin Rochlin in 1972 to mock the typical questions heterosexual people ask homosexual people. Five participants believed that their 'heterosexuality' was an imposed social model. The only openly gay participant (M6) wrote "my imposed heterosexuality was caused by a bad educational system and religion", while W1 and M2 thought that this was due to childhood environment and society in general. Only W4 and M4 believed that their heterosexuality was caused by their attraction to the opposite sex.

In this question heterosexuality was made explicit and some of the participants recognised its imposed social role, which should be discussed in primary school EFL as part of sexual identities, as these are easily identified by everyone and do exist all over the world. 


\subsection{Sexual identity issues in primary school education}

1. Have you ever experienced cases of homophobic bullying at primary school?

Six participants had witnessed it, but had never experienced it personally. M2 stated that when he witnessed homophobic bullying teachers' reactions were always limited to a mild reproach. He also stated that some parents encouraged homophobia. This was confirmed by W1 who wrote that "teachers and adults in general do not react when faced with homophobic bullying"; M5 felt that this lack of reaction from primary school teachers is based on the fact that they have highly entrenched ideas about traditional gender roles. M1 admitted that when he witnessed incidents of homophobia he tried to avoid being bullied and when teachers intervened they reproached both victim and bully.

The participants' responses underline the importance of recognising cases of homophobia and what action teachers should take. For the purpose of this research, it was important for these ten training teachers to be aware of the devastating effects of homophobic bullying in education (FELGTB, 2013). M6 argued that victims of homophobic bullying should react and face the problem in order to avoid feeling isolated and attempting suicide. In our view, some of these victims lack the energy and strength to deal with their frustration and desperation. It is therefore necessary for all teachers to be alert of vulnerable pupils, to respect them and empathise with them if they are not psychologically as strong as others, and find ways to help and support them.

2. Have you ever received any kind of training on how to deal with homophobia at primary school? If yes, where and how?

Nobody admitted having received any training. Only M2 stated that homophobia was discussed, though superficially, at university. Crucially, their responses are in line with our initial hypothesis that primary school English language teachers in Spain generally do not receive any kind of training on how to counter homophobia and heterosexism.

3. Do you think it is easier to discuss sexual identity issues with children or adults? Why?

Five participants believed it is easier with adults, four with children and for W2 it is the same. M6 wrote that adults are more difficult to 'manipulate'; whilst W1 objected to discussing sexual identity with primary school pupils as children "would express their family's views on the subject rather than their own opinions"; this might be true, but also school peers can be very influential. W3 thought that children are unable to contribute to sexual discourses in the same way as adults since the latter have more experience. M1 argued that children at primary school do not have sexual impulses or desires and felt that children would accept what the teacher says unquestioningly without a true understanding of the issue. However, as discussed in 2.1, we believe that this is a myth as children are sexed beings and are capable of critical thinking on issues related to sexual identities (Sears, 1999). W4, who worked in a Catholic school at the time she took part in this survey, was concerned about parental reaction and stated that "the strong legislation in favour of children's rights could be used against us by parents at any time".

As partly expected, half of the cohort believed it is easier to discuss sexual identities with adults than children. However, Chesnoff and Cohen (1996) demonstrated that children do possess critical spirit and are willing to know more about sexual and gender identities, 
to do this all children's view on the subject should be heard and shared with the rest of the class in order to promote critical thinking. Furthermore, it is important to highlight that when we treat sexual identities in primary education, we do not discuss sex, but rather social representations in a specific context.

4. Would you worry about parental reaction if you considered addressing queer issues? Five participants replied they would. However, W3 wrote that she would not be worried about it as she felt that parents should be aware that queer issues are addressed for educational purposes. W4 was very worried about losing her job due to parental reactions. M1 wrote that "parents can be more dangerous than children when they complain and some parents would not approve of their children discussing sexuality issues at school".

This resulted to be a recurrent problem for the participants. Perhaps educators should request parents' permission to address queer issues, somehow involve them in the process, or try to persuade those not in favour of discussing these issues in education that homophobia and heterosexism are social injustices and forms of discrimination which, like others, should be dealt with in schools from an early age. To do this, teachers and educators need allies such as colleagues, other school staff, directors and a supportive legislation.

5. Have you ever discussed queer issues in a class, with an individual student, or with your teachers?

Seven participants admitted having discussed queer issues at school or university, but only superficially, and five had discussed these issues with their teachers 'in a normal way', which sounds promising. M1 wrote that he brought up the subject with school mates and teachers because "I have always been interested in the "culture vs. nature' debate". In his view, there is a balance between culture and nature which are complementary rather than necessarily opposed. Whilst M2 described a queer pedagogical situation: "During my training period the kids asked me if I had a girlfriend, I said no, I said I had a boyfriend. They told me that I did not look gay. For me this is a way to make them aware, especially because they appreciated and admired me". Like most adults, children assume that everyone is heterosexual. However, this participant broke this imposed rule by stating that he had a boyfriend. This queer situation could be exploited pedagogically by asking the pupils, for example, what looking gay and looking straight actually mean. This incident also shows that pupils in Spain have their own knowledge of what is queer and what is not. According to Nelson (1999), English language teachers should be able to create queer pedagogical opportunities for discussion, like this one, rather than merely wait for them to occur.

\subsection{Queer issues in EFL primary education}

1 Why is (or is not) discussing lgbti issues in primary school EFL education important?

Everybody believed it is important, but half of the cohort would discuss lgbti issues in the last two years of primary school. W1 thought it is important to normalise queer issues in primary education because children need to be able to discuss them freely. W3 argued that discussing these issues can prevent future problems amongst the students; M5 believed they should be treated just like other social problems, like abortion. M1 underlined the importance of discussing these issues in education because they are not normally treated at 
home; M4 observed that children need training on how to deal with lgbti issues and W4 expressed worries if the school is Catholic.

They answers are in line with what queer theory advocates: inclusion and discussion of queer issues in education in order to make children and educators aware of a social injustice that is usually never mentioned. There is a recurrent fear of discussing sexual identities in Catholic schools. Although this is somehow understandable, not all Catholic schools and school staff are against the idea of treating homophobia as a social injustice or dealing with it in different social contexts, thus creating a safe space for discussion.

\section{Would you integrate lgbti themes and discussions into the existing primary curriculum} for English language teaching? If yes, how?

M1 would prefer to do it in secondary education, or in the last two years of primary education. W1 would also do it from the last two years of primary school using games. W3 would do it as soon as possible in a social context, showing photos and videos. M2, M4 and M5 would do it trough cross curricular themes or when the issue comes up spontaneously; M3 when discussing family models, whilst W4 would try to avoid it altogether in a Catholic primary school. Just like in question 3 of 6.3, participants feel very cautious about treating sexuality issues with children; there is a generalised belief that children are supposed to be more aware and ready to deal with the issue in the last two years of Spanish primary school or in secondary school. As expressed by W3, we believe there is a need to introduce queer issues as soon as possible as part of social injustices, like different ethnicities or different abilities, since it is at an early age that children learn homophobia, and as they learn it, they can also learn to counter it by means of critical discussions in the primary school classroom (Chesnoff \& Cohen, 1996).

3. How is 'family' usually represented in a primary school EFL textbook? Which vocabulary do children learn? Which don't?

All participants agreed that 'family' is always portrayed as typically heterosexual with dad and mum, and son and daughter, all fulfilling traditional gender roles, thus admitting that primary school EFL textbooks are heterosexist. M3 argued that even young boys are portrayed as attracted to young girls and vice-versa. They also observed that the vocabulary pupils learn reflects this: mother, father, son, daughter, nephew, niece, grandparents, etc. M1 wrote that "not only does exclusion affect homosexual families, but also other 'family' members, such as step-fathers, step-mothers, ex-husbands, unmarried couples, and single parents", who are not normally considered acceptable or appropriate for discussions with children. Finally, W2 admitted that "nothing has changed since I was a child, as nowadays pupils learn the same vocabulary in English that I had also learnt".

Learning the vocabulary in this questionnaire might have made the participants aware of the heterosexism present in primary school English language textbooks and the typical vocabulary that pupils learn, which has not changed in current EFL textbooks even if our society has changed. The participants made it clear that a more diverse vocabulary is needed, especially to avoid exclusion. In our opinion, teaching and using appropriate language and queer terminology in EFL education is of paramount importance and should be done as early as possible. 


\section{Conclusions}

On the basis of the participants' responses, it seems feasible to apply queer theory to English language teaching at primary school level in Spain by prompting critical thinking and inquiry, even if sexual identity issues are not included in the EFL textbooks. Furthermore, our initial predictive hypothesis that the sample cohort never received any training on how to deal with homophobia and heterosexism has also been confirmed. This lack of preparation and training is likely to lead to unprofessional teaching practice and a failure to respond adequately to pupils' needs in the area of sexual identity in EFL. The main limitation to this study is that the cohort decided to participate voluntarily and seemed to have already some interests in queer issues. It is possible that another sample group might have given different points of view. However, participants did not seem to possess sufficient knowledge to be able to counter homophobia and heterosexism in primary school EFL teaching and, most importantly, they expressed need and motivation to change this; thus we can consider our findings to be sufficiently representing.

The questionnaire used in this study is just the first step for gathering primary raw data. As a follow up step, we have decided to conduct a discussion with the same focus group in order to clarify some of their statements, to debate the issues in more depth, to include talks on trans and intersexual people, who seem to be made even more invisible in education, and, above all, to analyse the application of queer pedagogy to primary school EFL education.

\section{BiblographicAl REFERENCES}

Barozzi, S. (2010). Queer theory and English as a Foreign Language (EFL): A pre-service primary school teachers' perspective. (Unpublished Master's dissertation). University of Granada. Granada.

Barozzi, S. and Guijarro Ojeda, J.R. (2014). "Discussing sexual identities with pre-service primary school English-language teachers from a Spanish context", in Perspectives in Education, 32, 3: 131-145.

Bickmore, K. (1999). "Why discuss sexuality in elementary school?", in W. J. Lett and J. T. Sears (eds.), Queering Elementary Education. Advancing the Dialogue about Sexualities and Schooling. New York: Rowman \& Littlefield Publishers, Inc., 15-25.

Blair, A. and Cadwallader, J. (2009). Galaxy 3. Oxford: Oxford University Press.

BOE (2006). Ley Orgánica 2/2006, de 3 de mayo, de Educación. Madrid.

Butler, J. (1990). Gender Trouble. Feminism and the Subversion of Identity. New York: Routledge.

Chasnoff, D. and Cohen, H. (Directors). (1996). It's Elementary. Talking about Gay Issues in Schools [Documentary]. United States of America: Women Educational Media.

Chasnoff, D. and Cohen, H. (Directors). (2006). It's Still Elementary [Documentary]. United States of America: Women Educational Media.

FELGTB (2013). Acoso escolar (y riesgo de suicidio) por orientación sexual e identidad de género: Fracaso del sistema educativo, available from http://www.felgtb.org/rs/2157/ d112d6ad-54ec-438b-9358-4483f9e 98868/671/filename/informedefensor-17m13.pdf, accessed 28 December, 2013.

Foucault, M. (1976). Histoire de la Sexualité 1. La Volonté de Savoir. Paris: Éditions Gallimard. 
Gallardo Linares, F. and Escolano López, V. (2009). Informe sobre la Diversidad Afectivo-Sexual en la Formación de Docentes. Evaluación de Contenidos LGBT en la Facultad de CC. EE. de Málaga. Málaga: CEDMA.

García Gómez, A. (2006). "Sneaking Gender into the EFL Class", in Porta Linguarum, 5: 77-89.

Guijarro Ojeda, J.R. (2006). "Enseñanzas de la teoría Queer para la didáctica de la lengua y la literatura extranjeras", in Porta Linguarum, 6: 53-66.

Guijarro Ojeda, J.R. and Ruiz Cecilia, R. (2013). "Perceptions of Spanish EFL trainee teachers on the introduction of queer issues in the classroom", in Onomazéin, 27: 193-206.

Harris, M.; Nightingale, J. and Owen, N. (1995). "Health care professionals'experience, knowledge, and attitudes concerning homosexuality", in Journal of Gay and Lesbian Social Services, 2, 2: 91-107.

Herdt, G, and Boxer, A. (1993). Children of Horizon. Boston: Beacon Press.

Herek, G. (1998). "The attitudes toward lesbians and gay men (ATLG) scale", in Davis et al., (eds.), Handbook of Sexuality-related Measures. California: Sage Publications, 392-394.

Jagose, A. (1992). Queer Theory: An Introduction. New York: New York University Press.

Jennings, K. (1999), "Foreword", in W. J. Letts and J. T. Sears (eds.), Queering Elementary Education. Advancing the Dialogue about Sexualities and Schooling. New York: Rowman \& Littlefield Publishers, Inc., ix-xii.

Madrid, D. (2011)."Racial and social discrimination in the EFL class: The case of the Roma minority", in Porta Linguarum, 15: 71-91.

Nelson, C. (1999). "Sexual identities in ESL: Queer Theory and classroom inquiry", in TESOL Quarterly, 33, 3: 371-391.

Nelson, C. (2002) "Why Queer Theory is useful in teaching: A perspective from English as a second language teaching", in Journal of Gay \& Lesbian Social Services, 14, 2: 43-53.

Nelson, C. (2009). Sexual Identities in English Language Education: Classroom Conversations. New York: Routledge.

Pichardo Galán, J.I. et al. (2007). Actitudes ante la Diversidad Sexual de la Población Adolescente de Coslada (Madrid) y San Bartolomé de Tirajuana (Gran Canaria). Madrid: COGAM.

Read, C. and Soberón, A. (2009). Bugs World 2. Oxford: MacMillan.

Robinson, K. and Jones Díaz, C. (2006). Diversity and Difference in Early Childhood Education. London: Open University Press.

Sears, J. (1999). "Teaching queerly: Some elementary propositions", in W. J. Letts and J. Sears (eds.), Queering Elementary Education. Advancing the Dialogue about Sexualities and Schooling. New York: Rowman \& Littlefield Publishers, Inc., 3-14.

Thornbury, S. (1999). "Window-dressing vs. cross-dressing in the EFL sub-culture", in Folio, 5, 2: $15-17$. 